\title{
Epidemiology of injury in elite and subelite female gymnasts: a comparison of retrospective and prospective findings
}

\author{
Gregory S Kolt, Robert J Kirkby
}

\begin{abstract}
Objectives-An 18 month prospective injury survey was conducted on 64 Australian elite and subelite female gymnasts. The aims were to determine the rate of injury, anatomical location, and types of injury incurred by female competitive gymnasts, and to compare the findings with data collected retrospectively from the same sample of gymnasts.
\end{abstract}

Methods-The gymnasts recorded (weekly) in an injury record booklet the number of hours trained and information on any injuries suffered over that week.

Results-The sample reported 349 injuries, a rate of 5.45 per person (6.29 for the elite and 4.95 for subelite gymnasts) over the 18 month survey. Injuries to the ankle and foot $(31.2 \%)$ were the most commonly reported, followed by the lower back $(14.9 \%)$. The most prevalent type of injury were sprains $(29.7 \%)$, followed by strains $(23.2 \%)$, and growth plate injuries $(12.3 \%)$. The elite gymnasts reported that, for each injury, they missed fewer training sessions $(p=0.01)$, but modified more sessions $(p=0.0001)$ than their subelite counterparts. Further, the elite gymnasts spent $21.0 \%$ of the year training at less than full capacity because of injury. Although a significantly higher number of injuries were recorded in the prospective study $(p=0.0004)$, no differences were found between the distribution of injury by anatomical location or type between the two methods of data collection.

Conclusions-The findings have important implications in terms of training procedures and periodic screening of gymnasts.

(Br F Sports Med 1999;33:312-318)

Keywords: gymnastics; injury; elite; epidemiology; training

Participation in sport and recreational activities has increased in recent times, ${ }^{12}$ particularly within the female population. ${ }^{3}$ This increased participation is not surprising given the evidence of the physical ${ }^{4}$ and psychological $^{5}$ benefits of exercise. Gymnastics is one of the sports that has undergone rapid growth in participation rates. ${ }^{6}$ This growth, along with the decreasing age of children entering the sport, ${ }^{7}$ has, as Maffulli et al pointed out, exposed a growing number of gymnasts to potential injury.

Given the expense of treatment, the loss of sport participation time, the risk of long term or even permanent disability, and the consequent reduced quality of life, injuries in sport can burden both the individual and team (in terms of sport performance and non-sport aspects of life), as well as having a broader societal effect. ${ }^{9}$ Consequently, authorities - for example, the World Health Organization ${ }^{10}$ - have recognised the importance of continuing research on sports injuries. This has highlighted the need for appropriate epidemiological data for the planning, development, and evaluation of measures to prevent such injuries. ${ }^{11}$

Epidemiological techniques used to investigate gymnastic injuries have included both retrospective and prospective surveys, as well as case studies. ${ }^{12}{ }^{12-25}$ Several epidemiological investigations into gymnastic injury have relied on retrospective data collection, ${ }^{16}{ }^{20}{ }^{23}$ a method dependent on memory recall and thus involving the risk of "retrospective contamination" ${ }^{26}$ That is, reports of previous events (injuries) could have been exaggerated as a way of accounting for subsequent difficulties (recent performance problems). Given the wide acceptance in the epidemiological arena that prospective investigations are methodologically superior to those conducted retrospectively, ${ }^{27}$ many gymnastic injury studies have adopted the prospective approach. ${ }^{7145^{1921-25} 28}$ It is notable that, despite the reported problems of retrospective injury surveys, no published investigations have compared data collected retrospectively and prospectively from the same gymnastic sample.

Previous studies of gymnastic injury have reported considerable differences in injury rates (table 1). These variations could be due to the definition of injury used by the investigators. For example, Snook ${ }^{23}$ considered only injuries that were serious enough to bring to the attention of a doctor, whereas Sands et a $l^{2}$
Accepted for publication 24 May 1999 
Table 1 Studies of injury rates in gymnasts

\begin{tabular}{|c|c|c|c|}
\hline Reference & Design & Participants & Injury rate (\%) \\
\hline Snook $^{23}$ & Retrospective (5 years) & 70 college gymnasts (age not reported) & 94 \\
\hline \multirow{2}{*}{ Garrick and Requa ${ }^{14}$} & Prospective (2 years) & 98 high school gymnasts (age not reported) & 39.8 \\
\hline & Prospective ( 1 year) & 317 high school and college gymnasts (age range 6-21) & 33.4 \\
\hline Lowry and LeVeau ${ }^{20}$ & Retrospective (10 months) & 4215 competitors and non-competitors (age not reported) & $42-76$ \\
\hline Weiker $^{25}$ & Prospective (9 months) & 873 competitive club gymnasts (mean age 11.1 ) & 12 \\
\hline Pettrone and Ricciardelli ${ }^{21}$ & Prospective (7 months) & 2558 club (beginner to elite) gymnasts (age not reported) & $0.7-5.3$ \\
\hline Kerr and Minden ${ }^{16}$ & Retrospective (2 years) & 41 elite gymnasts (mean age 14.5 ) & 83 \\
\hline Caine $e t a l$ & Prospective ( 1 year) & 50 competitive club gymnasts (mean age 12.6 ) & 294 \\
\hline Lindner and Caine ${ }^{19}$ & Prospective (3 years) & 178 competitive club gymnasts (age range $7-15$ ) & 50.6 \\
\hline Kerr $^{15}$ & Prospective ( 8 months) & 24 elite gymnasts (mean age 18.6 ) & 250 \\
\hline Dixon and Fricker ${ }^{13}$ & Retrospective (10 years) & 74 elite gymnasts (age range $9-19$ ) & 200 (per year) \\
\hline Sands et $a l^{2}$ & Prospective (5 years) & 37 college gymnasts (age not reported) & Not reported \\
\hline Wadley and Albright ${ }^{24}$ & Prospective (4 years) & 26 college gymnasts (age not reported) & 200 \\
\hline Kolt and Kirkby ${ }^{12}$ & Retrospective (1 year) & 162 competitive gymnasts (mean age 12.6 ) & 198 \\
\hline
\end{tabular}

defined injury as any damaged body part that interfered with training.

A further complicating factor in interpreting the previously reported injury rates is the level of gymnastic ability of participants. For example, Kerr and Minden ${ }^{16}$ surveyed only elite gymnasts (including contenders for the Canadian National Team), while Pettrone and Ricciardelli ${ }^{21}$ included non-competitive club level gymnasts in their sample. These differences in ability level are likely to be linked to exposure time to injury; typically training hours increase with the ability levels. Consequently, compared with recreational club level gymnasts, ${ }^{21}$ elite gymnasts ${ }^{7}$ are likely to train for longer, and thus increase their exposure time to injury. Unfortunately, relatively few studies have reported injury as a function of exposure, ${ }^{12} 719222528$ but those who have used this approach have reported findings ranging between 0.5 injuries per 1000 hours of participation $^{19}$ to 22.7 injuries per 1000 hours. $^{22}$

In addition to problems of definition of injury and the nature of samples, there are two further limitations of previous gymnastic injury research. The first is the relative paucity of published epidemiological investigations of gymnastic injury outside of the United States, and the second is that a large number of studies (by use of their injury definition) have not included the more minor injuries associated with gymnastics - for example, Snook. ${ }^{23}$ Previous research ${ }^{12} 1516$ suggests that, regardless of injury and pain, many gymnasts will continue to train with modified schedules.

In the light of the previously reported gymnastic injury studies, and the methodological problems of much of that literature, this study was carried out. The primary aim was to determine the rate, anatomical location, and type of injury incurred by elite and subelite female competitive gymnasts in Australia. A particular purpose of the study was to compare the findings of data collected prospectively (this study) with retrospectively collected data from the same sample of gymnasts (as reported by Kolt and Kirkby ${ }^{12}$ ).

\section{Methods}

SUBJECTS

The participants were 64 female artistic gymnasts, ranging in age from 11 to 19 years (mean (SD) $12.6(1.7)$ ). The sample included 24 "elite" gymnasts (mean (SD) age 12.5 (1.1) years), who were training between 29 and 36 hours (mean (SD) 33.3 (2.4)) a week, and 40 "subelite" gymnasts (mean (SD) age 14.4 (1.6) years), who were training between 4 and 25 hours (mean (SD) 16.8 (4.5)) a week. The elite gymnasts, subjects who had been identified by the Australian Gymnastic Federation as potential candidates for the national team, in particular, the 1996 and 2000 Olympic Games, were training at "high performance training centres" set up by the state sports institutes and Australian Gymnastic Federation at several locations around the country. Most gymnasts in this group had high national rankings and included members of national teams. The subelite gymnasts were those who were competing at a state and national championship level, but in a stream that excluded the elite gymnasts. Participants in this study were drawn from 17 training centres (seven elite and 10 subelite, and involving 23 coaches) spread through five mainland states and one territory of Australia.

It should be noted that the participants in this study formed a subgroup of the 162 gymnasts involved in the retrospective study of Kolt and Kirkby. ${ }^{12}$ In fact, all 162 gymnasts investigated in the earlier study commenced participation in the present 18 month prospective assessment of injuries. Of the 98 gymnasts who had discontinued their participation in the investigation, 88 had retired from the sport, two had moved interstate and could not be traced, three had changed their affiliation to a club not involved in the study and did not continue their weekly recording of injury data, and five had lost their recording booklets (reportedly because their coach moved overseas and took the information with him). It is not surprising, given the age range of the gymnasts (11-19 years), that more than half of the original sample had retired from gymnastics over the 18 month study period. Researchers in western societies ${ }^{29}{ }^{30}$ have suggested that, despite sport participation rates rising during early childhood, they dramatically decline during adolescence. For example, the Australian Sports Commission ${ }^{31}$ reported that, although $64 \%$ of younger children are involved in organised physical activity, $36 \%$ of $13-18$ year olds do not participate in sport and, of those who do participate, $20 \%$ are at risk of dropping out of their current activities. It could be, as suggested by Weiss and Petlichkoff, ${ }^{32}$ that many children who appear to drop out of a sport actually transfer to other physical activities. 
Table 2 Injury location for the overall sample, elite, and subelite gymnasts

\begin{tabular}{|c|c|c|c|c|c|c|}
\hline \multirow[b]{3}{*}{ Location of injury } & \multicolumn{6}{|c|}{ Number of injuries } \\
\hline & \multicolumn{2}{|c|}{$\begin{array}{l}\text { Overall sample } \\
(n=349)\end{array}$} & \multicolumn{2}{|c|}{$\begin{array}{l}\text { Elite gymnasts } \\
(n=151)\end{array}$} & \multicolumn{2}{|c|}{$\begin{array}{l}\text { Subelite gymnasts } \\
(n=198)\end{array}$} \\
\hline & $n$ & $\%$ & $n$ & $\%$ & $n$ & $\%$ \\
\hline Head & 4 & 1.1 & 1 & 0.7 & 3 & 1.5 \\
\hline Spine and trunk & 60 & 17.2 & 17 & 11.2 & 43 & 21.9 \\
\hline Lower back & 52 & 14.9 & 14 & 9.2 & 38 & 19.4 \\
\hline Neck/trunk & 8 & 2.3 & 3 & 2.0 & 5 & 2.6 \\
\hline Upper limb & 74 & 20.9 & 41 & 26.8 & 33 & 16.4 \\
\hline Shoulder & 15 & 4.3 & 7 & 4.6 & 8 & 4.1 \\
\hline Elbow/forearm & 24 & 6.9 & 19 & 12.4 & 5 & 2.6 \\
\hline Wrist/hand & 34 & 9.7 & 15 & 9.8 & 19 & 9.7 \\
\hline Lower limb & 205 & 59.0 & 90 & 58.7 & 115 & 59.1 \\
\hline Ankle/foot & 109 & 31.2 & 47 & 30.7 & 62 & 31.6 \\
\hline Lower leg & 30 & 8.6 & 10 & 6.5 & 20 & 10.2 \\
\hline Knee & 47 & 13.5 & 25 & 16.3 & 22 & 11.2 \\
\hline Hip & 20 & 5.7 & 8 & 5.2 & 12 & 6.1 \\
\hline Other & 6 & 1.7 & 4 & 2.6 & 2 & 1.0 \\
\hline
\end{tabular}

Of the initial 162 gymnasts, 74 were still participating in gymnastics at the end of the 18 month prospective survey period, and full data were collected from 64 of these (a response rate of $86 \%$ ).

\section{TEST INSTRUMENTS}

Participants were requested to complete an injury record booklet on a weekly basis. Specifically, the gymnasts were requested to record the number of hours trained, and information about any injuries that had been incurred or that had interfered with their training over that week. Details were sought on anatomical location of injury, type of injury, nature of medical advice and treatment sought, number of full training sessions/competitions missed as a result of the injury, and the number of training sessions modified as a result of the injury. Participants indicated in the booklet whether reported injuries were new or continuing. This inventory was adapted from that used previously with gymnasts of a similar age and had been tested for comprehensibility. ${ }^{12} 18$ For the purpose of this study, "injury" was defined as any gymnastics related physical damage that caused the gymnast to miss or modify one or more training sessions, competitions, or both. Gymnasts were instructed not to include blisters (a common occurrence in gymnastics) as injuries.

\section{PROCEDURE}

After approval had been given by the Australian Gymnastic Federation, the coaches of the target gymnasts were contacted. The investigator then travelled to each training centre and,

Table 3 Injury type for the overall sample, elite, and subelite gymnasts

\begin{tabular}{|c|c|c|c|c|c|c|}
\hline \multirow[b]{3}{*}{ Type of injury } & \multicolumn{6}{|c|}{ Number of injuries } \\
\hline & \multicolumn{2}{|c|}{$\begin{array}{l}\text { Overall sample } \\
(n=349)\end{array}$} & \multicolumn{2}{|c|}{$\begin{array}{l}\text { Elite gymnasts } \\
(n=151)\end{array}$} & \multicolumn{2}{|c|}{$\begin{array}{l}\text { Subelite gymnasts } \\
(n=198)\end{array}$} \\
\hline & $n$ & $\%$ & $n$ & $\%$ & $n$ & $\%$ \\
\hline Fracture & 29 & 8.3 & 14 & 9.2 & 15 & 7.6 \\
\hline Dislocation & 2 & 0.6 & 2 & 1.3 & 0 & 0.0 \\
\hline Sprain & 100 & 29.7 & 22 & 14.4 & 78 & 39.8 \\
\hline Strain & 81 & 23.2 & 31 & 20.3 & 50 & 25.5 \\
\hline Tendinitis & 24 & 6.9 & 14 & 9.2 & 10 & 5.1 \\
\hline Inflammation & 39 & 11.2 & 20 & 13.1 & 19 & 9.7 \\
\hline Contusion & 21 & 6.0 & 8 & 5.2 & 13 & 6.6 \\
\hline Growth plate & 43 & 12.3 & 38 & 24.8 & 5 & 2.6 \\
\hline Other (e.g. cuts from equipment) & 10 & 2.9 & 4 & 2.6 & 6 & 3.1 \\
\hline
\end{tabular}

with the coaches' permission, attended a training session to distribute and explain the injury record booklets and a statement of informed consent for parents or guardians.

To enhance compliance of the weekly recording of injury and training data over the 18 month prospective survey period, all coaches were contacted monthly by telephone (12 occasions) or letter (six occasions). This regular contact was to remind coaches to encourage and check the recording of the data and to discuss any problems. At three month intervals during the 18 month prospective survey period, the completed sections of the injury record booklets were collected from the gymnasts via their coaches.

\section{Results}

The total sample $(n=64)$ reported 349 injuries for the 18 month survey period (an injury rate of 5.45 injuries per gymnast, 3.64 per gymnast per 12 month period). For the survey period, the 24 elite gymnasts sustained 151 injuries (6.29 per gymnast; 4.19 per gymnast per year) while the 40 subelite gymnasts reported 198 injuries (4.95 per gymnast; 3.30 per gymnast per year). Analysis showed that the injury rate for the elite gymnasts was significantly higher $(t$ $(62)=2.01, p=0.05)$ than for the subelite gymnasts. In terms of gymnastic participation over the 18 month prospective injury surveillance period, the 64 gymnasts reported 105583 hours of training (for an overall injury rate of 3.31 injuries per 1000 hours of training). The elite gymnasts reported 57383 hours of training (2.63 injuries per 1000 hours of training), and the subelite participants, 48200 hours (4.11 injuries per 1000 training hours). Analysis by unpaired $t$ test showed that the injury rate per 1000 hours of training for the elite gymnasts was significantly lower than that for the subelite gymnasts $(t(62)=-2.51$, $\mathrm{p}=0.01)$. It is notable that, according to their diaries, no gymnasts remained uninjured during the 18 month survey period and that $96 \%$ of the elite gymnasts and $65 \%$ of the subelite subjects reported that they sustained three or more injuries over the 18 months.

Table 2 shows that, for the total sample, injuries were distributed throughout the body. The most common location was ankle and foot (31.2\% of total injuries), followed by lower back $(14.9 \%)$, knee $(13.5 \%)$, and wrist and hand $(9.7 \%)$. The elite gymnasts reported the most common location of injury to be the ankle and foot $(30.7 \%)$, followed by the knee $(16.3 \%)$, the elbow and forearm $(12.4 \%)$, the wrist and hand $(9.8 \%)$, and the lower back $(9.2 \%)$. For the subelite group, the most common injury sites were the ankle and foot (31.6\%), lower back (19.4\%), knee $(11.2 \%)$, lower leg $(10.2 \%)$, and wrist and hand $(9.7 \%)$. $\chi^{2}$ analysis showed a significant difference between the elite and subelite groups in anatomical location of injury $\left(\chi^{2}(10, \mathrm{n}=64)=\right.$ $24.51, \mathrm{p}=0.006)$. The data from table 3 suggest that differences between the groups were likely to be explained by the distribution of injuries to the lower back and knee regions. 
Table 4 Comparison of retrospective (Kolt and Kirkby ${ }^{12}$ ) and prospective injury data (current investigation)

\begin{tabular}{|c|c|c|c|c|c|c|}
\hline \multirow[b]{2}{*}{ Injury variable } & \multicolumn{3}{|c|}{ Retrospective data (Kolt and Kirkby ${ }^{12}$ ) } & \multicolumn{3}{|c|}{ Prospective data (current investigation) } \\
\hline & $\begin{array}{l}\text { Total } \\
(n=162)\end{array}$ & $\begin{array}{l}\text { Elite } \\
(n=47)\end{array}$ & $\begin{array}{l}\text { Subelite } \\
(n=115)\end{array}$ & $\begin{array}{l}\text { Total } \\
(n=64)\end{array}$ & $\begin{array}{l}\text { Elite } \\
(n=24)\end{array}$ & $\begin{array}{l}\text { Subelite } \\
(n=40)\end{array}$ \\
\hline Total injuries per year & 321 & 111 & 210 & 233 & 101 & 132 \\
\hline Injuries per gymnast per year & 1.98 & 2.36 & 1.83 & 3.64 & 4.19 & 3.30 \\
\hline Injuries per 1000 hours & 1.96 & 1.58 & 2.24 & 3.31 & 2.63 & 4.11 \\
\hline Most common injury location & $\begin{array}{l}\text { Ankle and foot } \\
(31.8 \%)\end{array}$ & $\begin{array}{l}\text { Ankle and foot } \\
(32.4 \%)\end{array}$ & $\begin{array}{l}\text { Ankle and foot } \\
(31.4 \%)\end{array}$ & $\begin{array}{l}\text { Ankle and foot } \\
(31.2 \%)\end{array}$ & $\begin{array}{l}\text { Ankle and foot } \\
(30.7 \%)\end{array}$ & $\begin{array}{l}\text { Ankle and foot } \\
(31.6 \%)\end{array}$ \\
\hline Most common injury type & $\begin{array}{l}\text { Sprain } \\
(29.6 \%)\end{array}$ & $\begin{array}{l}\text { Sprain } \\
(32.4 \%)\end{array}$ & $\begin{array}{l}\text { Sprain } \\
(28.1 \%)\end{array}$ & $\begin{array}{l}\text { Sprain } \\
(29.7 \%)\end{array}$ & $\begin{array}{l}\text { Growth plate } \\
(24.8 \%)\end{array}$ & $\begin{array}{l}\text { Sprain } \\
(39.8 \%)\end{array}$ \\
\hline Mean number of missed training sessions per injury & 3.7 & 4.1 & 3.5 & 1.4 & 0.5 & 2.0 \\
\hline Mean number of modified training sessions per injury & 20.4 & 34.4 & 13.0 & 14.0 & 23.1 & 7.0 \\
\hline Mean number of weeks missed per injury & 0.7 & 0.4 & 0.8 & 0.4 & 0.1 & 0.6 \\
\hline Mean number of weeks modified per injury & 3.1 & 3.7 & 2.7 & 2.1 & 2.4 & 1.8 \\
\hline Proportion of acute injuries & 58.3 & 44.1 & 65.7 & 64.2 & 50.3 & 75.0 \\
\hline Proportion of chronic injuries & 41.7 & 55.9 & 34.3 & 35.8 & 49.7 & 25.0 \\
\hline
\end{tabular}

The most common types of injury in the overall sample (see table 3 ) were sprains $(29.7 \%)$, followed by strains $(23.2 \%)$ and growth plate injuries $(12.3 \%)$. The most common types of injury reported by elite gymnasts were growth plate injuries $(24.8 \%)$, followed by strains $(20.3 \%)$ and sprains $(14.4 \%)$. The subelite subjects reported a predominance of sprains $(39.8 \%)$, followed by strains $(25.5 \%)$ and non-specific inflammatory injuries $(9.7 \%)$. The elite and subelite gymnasts reported a significantly different distribution of injury types $\left(\chi^{2}(8, n=64)=57.19, p=0.0001\right)$. This difference appeared to be due to the higher proportion of subelite gymnasts reporting sprains and the higher proportion of elite gymnasts reporting growth plate injuries.

The injury data, in terms of training time missed or modified, were analysed for differences between the elite and subelite groups. As four comparisons were made, Bonferroni adjustments were used to protect against Type 1 errors and the $\alpha$ rate was reduced to 0.013 . The average number of training sessions missed per injury for elite gymnasts (0.5) and subelite gymnasts (2.0) differed significantly $(t$ $(62)=-2.54, p=0.01)$. The mean number of training sessions modified as a result of injury by the elite group (23.1 sessions) was significantly higher $(t(62)=4.47, \mathrm{p}=0.0001)$ than for the subelite group (7.0 sessions). The number of weeks missed because of injury was also significant; the elite gymnasts missed an average of 0.05 weeks per injury compared with 0.57 for the subelite subjects $(t(62)=$ $-2.62, \mathrm{p}=0.009)$. There were, however, no significant differences between the groups in terms of number of weeks of training modified. As a result of each injury, the elite gymnasts modified 2.4 weeks of training compared with 1.8 for the subelite participants $(t(62)=1.40$, $\mathrm{p}=0.10)$.

A review of the total injuries reported by the sample indicated that $64.2 \%$ could be classified as acute (of sudden onset) and $35.8 \%$ could be classified as chronic (related to overuse). Of the injuries reported by the elite gymnasts, 50.3\% could be classified as acute and $49.7 \%$ as chronic. For the subelite group, $75 \%$ of the injuries reported were viewed as acute and $25.0 \%$ as chronic. $\chi^{2}$ analysis indicated that more elite gymnasts were more likely to report overuse injuries $\left(\chi^{2}(1, \mathrm{n}=64)=22.75, \mathrm{p}=\right.$ 0.0001).

Table 4 shows comparisons between the current prospective injury data and the data collected retrospectively from the same sample for injuries sustained during the 12 month period immediately before the commencement of the 18 month prospective survey (as reported in Kolt and Kirkby ${ }^{12}$ ). Differences between the retrospective and prospective injury data were assessed by $t$ tests and $\chi^{2}$ analyses. As nine comparisons were made, Bonferroni adjustments were used to protect against Type 1 errors, and the $\alpha$ rate was adjusted to 0.006 .

The mean number of injuries per gymnast per year in the prospective assessment (3.64) was significantly higher than the 1.98 injuries reported in the retrospective assessment $(t$ (63) $=-3.74, \mathrm{p}=0.0004)$.

There was a trend toward a difference in the injury rates per 1000 hours (3.31 for the prospective versus 1.98 for the retrospective; $t$ $(353)=2.32, p=0.02)$, but this did not reach significance at the adjusted $\alpha$ level of 0.006 .

In terms of the average number of training sessions missed per injury, no significant difference $(t(353)=-1.40, \mathrm{p}=0.16)$ was found between the data from the retrospective assessment (3.7) and prospective survey (1.4). Similarly, there was no difference $(t$ (353) $=$ $-1.38, p=0.17$ ) between the average number of training sessions modified as a result of each injury for the retrospective (20.4) and prospective (14.0) surveys.

In relation to the number of weeks of training missed as a result of each injury, the findings from the retrospective study (0.7) did not differ significantly from those of the prospective survey $(0.4 ; t(353)=1.98, \mathrm{p}=0.05$; note the adjusted $\alpha$ level of 0.006 ). Also, the number of weeks of training modified as a result of each injury was not significantly different for the retrospective (3.1) and prospective (2.1) findings $(t(353)=1.87, \mathrm{p}=0.07)$.

The distribution of injury locations and the distribution of injury by type in the retrospective and prospective surveys (respectively) did not differ $\left(\chi^{2}(100, \mathrm{n}=226)=90.66, \mathrm{p}=0.73\right.$; $\left.\chi^{2}(64, \mathrm{n}=226)=65.59, \mathrm{p}=0.42\right)$. Similarly, the proportions of acute versus chronic injuries in the two injury surveys did not differ significantly $\left(\chi^{2}(1, \mathrm{n}=226)=0.554, \mathrm{p}=0.46\right)$. 


\section{Discussion}

All of the elite and subelite gymnasts in the present sample reported that they were injured during the survey period. This finding is alarming and should be considered by coaches and sports medicine personnel in the light of developing and implementing injury prevention programmes directed at gymnastic participants. Specifically, each gymnast reported an average of 3.64 injuries per 12 month period (4.19 for the elite gymnasts and 3.30 for the subelite gymnasts). Although the elite gymnasts reported significantly higher injury rates per year than the subelite participants, the reverse was true when considering injury in relation to training hours: the elite gymnasts reported 2.63 injuries per 1000 training hours while their subelite counterparts reported 4.11 injuries per 1000 hours. An explanation of this finding could be related to the difficulty of the skills being attempted by subelite participants. Often, gymnasts competing at the subelite level strive to achieve enough skills of a particular difficulty ranking to satisfy the judging and technical criteria required for their level of competition. As they are often attempting such skills with fewer training hours, less physical preparation, and with coaches who may not be as technically skilled as those of elite gymnasts, the risk of injury would appear to be greater.

The injury incidence rates were higher than those reported in most previous investigations. ${ }^{13} 1924$ This difference could be due to the fact that this study differed from earlier reports on several bases. Firstly, it should be noted that, in contrast with previous studies, many of the current subelite subjects were highly competitive, participating in national and state championships. Furthermore, most previous investigations ${ }^{7421}$ considered only injuries that resulted in missed time from training whereas the present investigation included injuries that resulted in modification of training without necessarily missing sessions. Finally, the response rate in this study $(86 \%)$ was well above the low rates of some of the previous investigations. ${ }^{18} 23$

The lower limb was the injury site most often reported by the gymnasts. Specifically, the ankle and foot incurred most injuries, consistent with most previous reports. ${ }^{13151619}$ The predominance of such injuries could be explained by the number of landings, often from a great height or from an element based on rotation or twisting, that the gymnasts perform. Other commonly reported injuries involved the lower back and knee, also concurring with the findings of previous investigations. ${ }^{13151619}$ That the wrist and hand was the most injured upper limb area further supports the earlier findings. ${ }^{719}$

The current finding for the overall sample that sprains and strains were the most commonly experienced gymnastic injuries confirmed a number of earlier reports. ${ }^{1421} 23$ It should be noted, however, that injuries to the growth plate areas of the body $(24.8 \%)$ were the most common type of injury incurred by elite gymnasts. In fact, it appears that the relatively high prevalence of growth plate injuries has only been reported in two previous investigations. ${ }^{12}{ }^{13}$ It could be that such injuries have been disguised by the varying classification system used by other investigators. As suggested by Kolt and Kirkby, ${ }^{12}$ growth plate injuries could have been hidden under headings such as "non-specific", ${ }^{19}$ "inflammations", ${ }^{7}$ and "other", ${ }^{20}$ and thus not identified as a separate area of concern. Given the serious nature of epiphyseal injuries, coaches should be aware of varying the usually repetitive nature of gymnastic training in order to reduce the cumulative forces placed on the epiphyseal regions of the body. In addition, the emphasis on appropriate physical conditioning (as part of training programmes) to prevent such injuries could also be beneficial to competitive gymnasts.

Interestingly, a review of injuries for the total sample indicated a predominance of acute injuries. However, when the elite and subelite groups were considered separately, it was found that only the subelite gymnasts reported a larger proportion of acute injuries. This finding concords with the earlier explanation that subelite gymnasts often attempt difficult skills (in a sometimes unprepared way) to satisfy the technical criteria required for their stream of competition.

In relation to the impact of injury on training, some important findings were evident. For each injury, the subelite gymnasts reported missing a significantly greater number of training sessions than their elite counterparts. As well, the elite gymnasts reported modifying a significantly greater number of training sessions than the subelite gymnasts when injured. This could be interpreted as meaning that the elite gymnasts, rather than missing training when injured, continued to participate in a modified manner, whereas the subelite gymnasts rested their injuries by not training. This finding could be a function of pressure from coaches to continue training in the presence of injury (to avoid the potential of physical deconditioning), or behaviour carried out by elite gymnasts to divert focus from their injuries and continue physical training. This explanation is likely in view of gymnasts in the elite group having been identified as potential candidates for the national team. That elite competitors were continuing to train with and through their injuries has important implications for coaches and sports medicine providers in establishing appropriate protocol for rehabilitation and return to sport from injury. Further, periodic musculoskeletal screening of gymnasts may assist in the identification of injuries that could be aggravated by further training, and allow appropriate rehabilitation protocol to be commenced.

In terms of time, injuries to elite gymnasts reduced their opportunity to train by $21 \%$. Subelite gymnasts spent $16.5 \%$ of training time at reduced capacity. The only other investigation to report data of this nature indicated that gymnasts in their sample spent $28.9 \%$ of the season at less than full training capacity because of injury. ${ }^{7}$ 
The present findings were compared with data collected retrospectively on the same sample, ${ }^{12}$ a procedure rarely reported in the literature. A major difference that emerged was the higher injury rate for the prospective survey. This could suggest that, when assessing injury data retrospectively, the more minor injuries may not be as readily recalled, thereby resulting in lower reported rates. By collecting information on injury prospectively, the problem of recall is reduced. This can result in more accurate details of injury being reported. It should be noted, however, that despite the differences in injury rates, the proportions of injury types and anatomical locations did not differ between the retrospective and prospective surveys. It could be concluded from these comparisons that the injury data are qualitatively the same but quantitatively different when collected using the two methods. Therefore the more easy to administer retrospective data collection method may be an efficient and useful way of determining the distribution of injury by anatomical location and type.

The findings of this study should be viewed in the light of four potential limitations. The first concerns the compliance of gymnasts with the weekly completion of the injury record over the 18 month survey period. As the investigator collected these data at three month intervals during this period, it is possible that subjects completed large portions of the injury record immediately before the time of collection, effectively introducing a retrospective component to this assessment. However, regular communication with coaches of gymnasts involved in the study (described above) indicated that this was unlikely: coaches encouraged gymnasts at a set time each week to complete their records and return them to the coach for safekeeping. Secondly, that the coaches collected the injury records from gymnasts could be interpreted as placing pressure on gymnasts to comply with the data collection. This data collection method may also result in some gymnasts not accurately disclosing certain injury data in the light of possible ramifications on team selection. However, as 20 of the 23 coaches involved in the study routinely kept a log of gymnasts' injuries before this investigation, this was thought to be unlikely. A further point about the present investigation concerns the relatively small number of elite gymnasts surveyed. However, it should be noted that this group consisted of about $70 \%$ of the total population of elite gymnasts in Australia at the time of the commencement of the study, and involved competitors from all regions of the country. Finally, this study could be criticised for the large variation in number of training hours (4-25 hours per week) of the subelite group. However, as the aim of the study was to compare gymnasts in the two streams of competition (elite and subelite) used in Australia and as the range of training hours for the subelite group appeared to be representative of that stream, it was not thought to be problematic.

Notwithstanding these methodological issues, the present study highlighted four par- ticular findings. Firstly, when exposure time to injury was considered, the subelite gymnasts reported a significantly higher injury rate than the elite participants. This could reflect lower levels of physical conditioning, less practice of particular skills, and attempting difficult skills to satisfy the technical requirements of that stream of competition. Secondly, the high proportion of growth plate injuries, particularly in the young elite gymnasts, is consistent with the repetitive nature of gymnastic training. Preventative physical conditioning programmes aimed at these high risk regions of the body may reduce this type of injury. Further, appropriate periodic assessments could enable such injuries to be diagnosed at an early stage, and modifications made to training programmes to assist the recovery process. Another notable finding was that the elite gymnasts reported a high proportion of time lost from training and competition as a result of injury, which was likely to affect performance potential. Caine et $a l^{7}$ in the only other study that reported data on accumulated time loss as a result of injury suggested that this information is important to athletes and coaches as it represents an index of the extent to which progress toward increased fitness and skill levels can be compromised as a result of injury. Finally, the mean number of injuries per gymnast over a 12 month period was significantly higher in the current prospective assessment than the previous retrospective survey. ${ }^{12}$ This possibly could be due to the fact that the data were collated at different times. However, as training typically goes in annual cycles, there is no reason to believe that injuries would vary significantly from year to year. A more likely explanation is related to the reliance on memory recall.

As outlined throughout this paper, the findings from this study have important implications for coaches and sports medicine personnel in relation to gymnastic training procedures, periodic physical monitoring of gymnasts, and maintaining and improving national and world rankings.

Preparation of this paper was supported in part by Physiotherapy Research Foundation grants 005/91 and 021/92, and the project was endorsed by the Australian Gymnastic Federation. We gratefully acknowledge Jeremy Cass for his assistance in the preparation and analysis of the data. Thanks are also extended to the gymnasts and gymnastic officials who, through their cooperation, enabled this study to be carried out.

1 Backx FGJ, Erich WBM, Kemper ABA, et al. Sports injuries in school-aged children. Am f Sports Med 1989;17:234-9. Homer S, Mackintosh S. Injuries in young female elite gymHomer S, Mackintosh S. Injuries in your

nasts. Physiotherapy 1992;78:804-8.
Kulpa PJ, White BM, Visscher R. Aerobic exercise in pregKulpa PJ, White BM, Visscher R. Aerobic exercis
nancy. Am f Obstet Gynecol 1987;156:1395-403.

4 Malina RM. Benefits of physical activity from a lifetime perspective. In: Quinney HA, Gauvin L, Wall AET, eds. Toward active living: proceedings of the international conference on physical activity, fitness, and health. Champaign, IL: Human Kinetics, 1994:47-53.

5 McAuley E. Enhancing psychological health through physical activity. In: Quinney HA, Gauvin L, Wall AET, eds. Toward active living: proceedings of the international conference on physical activity, fitness, and health. Champaign, IL. Human Kinetics, 1994:83-90.

6 Meeusen R, Borms J. Gymnastic injuries. Sports Med 1992; 15:337-56.

7 Caine D, Cochrane B, Caine C, et al. An epidemiologic investigation of injuries affecting young competitive female gymnasts. Am f Sports Med 1989;17:811-20.

8 Maffulli N, Bundoc RC, Chan KM, et al. Paediatric sports injuries in Hong Kong: a seven year study. Br f Sports Med 1996;30:218-21. 
9 Finch C, Ozanne-Smith J, Williams F. The feasibility of improved data collection methodologies for sports injuries (summary report). Melbou

10 World Health Organization. Regional targets in support of the regional strategy for health for all. Regional Office for Europe, 34th session. Copenhagen: WHO, 1984 (EUR/RS34/7).

11 Committee on Trauma Research. Injury in America. A continuing public health problem. Washington DC, National Academy Press, 1985.

12 Kolt GS, Kirkby RJ. Epidemiology of injuries in Australian female gymnasts. Sports Medicine, Training and Rehabilitation 1995;6:223-31.

13 Dixon M, Fricker P. Injuries to elite gymnasts over $10 \mathrm{yr}$ Med Sci Sports Exerc 1993;25:1322-9.

14 Garrick JG, Requa RK. Epidemiology of women's gymnastics injuries. Am f Sports Med 1980;8:261-4.

15 Kerr G. Injuries in artistic gymnastics. Fournal of the Canadian Athletic Therapy Association 1991 Apr:19-21.

16 Kerr G, Minden H. Psychological factors related to the occurrence of athletic injuries. Fournal of Sport $\mathbb{E}$ Exercise occurrence of athletic injuries.
Psychology 1988;10:167-73.

17 Kolt GS, Kirkby RJ. Injury, anxiety, and mood in competitive gymnasts. Percept Mot Skills 1994;78:955-62.

18 Kolt GS, Kirkby RJ. Injury in Australian female competitive gymnasts: a psychological perspective. Australian fournal of Physiotherapy 1996;42:121-6.

19 Lindner KJ, Caine DJ. Injury patterns of female competitive club gymnasts. Canadian fournal of Applied Sports Science 1990;15:254-61.

20 Lowry CB, LeVeau BF. A retrospective study of gymnastics injuries to competitors and noncompetitors in private clubs. Am f Sports Med 1982;10:237-9.
21 Pettrone FA, Ricciardelli E. Gymnastic injuries: the Virginia experience 1982-1983. Am f Sports Med 1987;15:59-62.

22 Sands WA, Shultz BB, Newman AP. Women's gymnastics injuries. Am f Sports Med 1993;21:271-6.

23 Snook GA. Injuries in women's gymnastics: a 5-year study. Am $\mathcal{F}$ Sports Med 1979;7:242-4.

24 Wadley G, Albright JP. Women's intercollegiate gymnastics. Injury patterns and "permanent" medical disability. $A m \mathcal{F}$ Sports Med 1993;21:314-20.

25 Weiker GG. Injuries in club gymnastics. Physician and Sportsmedicine 1985;13:63-6.

26 Brown G. Meaning, measurement and stress of life events. In Dohrenwend BS, Dohrenwend BP, eds. Stressful life events: their nature and effects. New York: Wiley \& Sons, 1974:217-34

27 Caine DJ, Caine CG, Lindner KJ. The epidemiologic approach to sports injuries. In Caine DJ, Caine CG, Lindner KJ, eds. Epidemiology of sports injuries. Champaign, IL: Human Kinetics, 1996:1-13.

28 Clarke KS, Buckley WE. Women's injuries in collegiate sports. Am F Sports Med 1980;8:187-91.

29 Robertson I. The sports drop-out: a time for change? Adelaide South Australia: South Australian College of Advanced Education, 1988 .

30 Weiss MR. Children's participation in physical activity. Pediatric Exercise Science 1993;5:205-9.

31 Australian Sports Commission. Sport for young Australians. Widening the gateway to participation. Canberra: Australian Sports Commission, 1991

32 Weiss MR, Petlichkoff LM. Children's motivation for participation in and withdrawal from sport. Identifying the missing links. Pediatric Exercise Science 1989;1:195-211.

\section{Take home message}

Injury rates in gymnastics are high. It could be that paying more attention to injury detection, examining training practices, and implementing appropriate periodic musculoskeletal screening would assist in reducing the detrimental effects of injury.

\section{Commentary}

This study contributes in significant ways to our understanding of injury assessment methods and injury occurrence in young gymnasts. It is the first study to compare retrospective and prospective approaches to the collection of injury data on the same sample of athletes. The authors report that accurate information may be obtainable through a retrospective approach, thus addressing the common criticisms of memory recall and "retrospective contamination" associated with this method of data collection. In addition, this study contributes to the literature by using exposure time to calculate injury rates and by comparing injuries of elite and subelite gymnasts. These findings, together with the reports of the training time compromised owing to injury, have important theoretical and practical implications for injury prevention.

GRETCHEN KERR

University of Toronto, Canada 